\title{
THE IMPACT OF TAX UNCERTAINTY ON IRREVERSIBLE INVESTMENT
}

\author{
RAINER NIEMANN
}

\section{CESIFO WORKING PAPER NO. 2075 \\ CATEgory 1: PubliC FinAnCE \\ August 2007}

Presented at CESifo Area Conference on Public Sector ECONOMics, April 2007

An electronic version of the paper may be downloaded

- from the SSRN website:

www.SSRN.com

- from the RePEc website:

- from the CESifo website:

www.CESifo-group.org/wp 


\title{
THE IMPACT OF TAX UNCERTAINTY ON IRREVERSIBLE INVESTMENT
}

\begin{abstract}
Tax legislation, fiscal authorities, and tax courts create tax uncertainty by frequent tax reforms and various different interpretations of the tax law. Moreover, investors generate modelspecific tax uncertainty by using simplified models that anticipate the actual tax base incorrectly. I analyze the effects of stochastic taxation on investment behavior in a real options model. The investor holds an option to invest in an irreversible project with stochastic cash flows. To cover the effects of both tax base and tax rate uncertainty, the investment's tax payment is modelled as a stochastic process. Increased tax uncertainty has an ambiguous impact on investment timing. The view that tax uncertainty depresses real investment is rejected. A higher expected tax payment delays investment. A higher tax rate on interest income affects investment timing ambiguously.
\end{abstract}

JEL Code: H25, G31.

Keywords: tax uncertainty, capital budgeting, real options, investment incentives.

Rainer Niemann

Institute of Accounting and Taxation

University of Graz

Universitaetsstr. 15 / FE

$8010 \mathrm{Graz}$

Austria

niemann@uni-graz.at 


\section{The Impact of Tax Uncertainty on Irreversible Investment}

\section{Introduction}

If taxes are integrated into capital budgeting, the investment models are typically based on deterministic tax rates and deterministic tax bases. In many countries, however, tax reforms occur frequently, especially after a new government is elected. As a consequence, taxpayers and tax accountants have to adapt to new tax rates and different methods of computing tax bases. Thus, tax policy can be regarded as a stochastic process which is difficult to be anticipated for investors. Furthermore, legislation is not the only source of tax uncertainty. Rather, there is tax uncertainty even if the tax law remains unchanged and if an investor has already made all economic decisions which are relevant for taxation. The reason is that taxpayers, fiscal authorities and tax courts may interpret tax laws and economic facts differently. Hence, tax uncertainty exists ex ante and ex post, i.e. prior to investment decisions and after investment decisions have been made. In the following, this type of tax uncertainty will be called fiscal tax uncertainty ${ }^{1}$.

However, tax uncertainty is not exclusively determined by state-run institutions. The investor himself may be responsible for uncertainty with respect to his tax payments. The reason is as follows: Since current tax laws are too complicated to be integrated in manageable models of capital budgeting, investors use simplified models of computing the tax base for an investment project. Thus, the taxes actually paid and the tax payments anticipated by the model can deviate. From the investor's perspective, the deviations are stochastic, even for unchanged tax laws. This kind of tax uncertainty can be called model-specific tax uncertainty.

Fiscal tax uncertainty especially affects long-term investment projects, whereas modelspecific tax uncertainty may occur for any duration of an investment project. As typically assumed, uncertain tax policy tends to depress investment. As a consequence, ignoring tax uncertainty would be misleading for investors and could probably induce harmful investment decisions. This paper analyzes whether this common view can be maintained when using an investment model based on real option theory. Moreover, I examine the impact of variations of different tax and non-tax parameters on individual investment behaviour. If the tax parameters do not affect investment decisions, the tax system is neutral. Tax neutrality can be defined with regard to the stochastic nature of the tax system.

The paper is structured as follows: After a literature review on stochastic taxation in section 2, I describe the investment model in section 3. In section 4, the investment problem is solved analytically. The impact of varying tax and non-tax parameters is examined in section 5 .

\footnotetext{
${ }^{1}$ Scholes et al. (2005), pp. 29 ff. provide an overview of the legislative and judicial system with regard to U.S. taxation.
} 
Section 6 provides some remarks on the existence of neutral tax systems under tax uncertainty. Section 7 concludes.

\section{Literature review}

The economic literature discusses the effects of tax uncertainty since more than two decades. The starting point was the impact of uncertain tax policy on economic welfare, beginning in the 1970s. Weiss (1976) analyzes random taxes in the context of tax evasion. He concludes that tax uncertainty can be socially useful under specific conditions. Based on effective tax rates, Auerbach / Hines (1987) show that anticipated changes in taxes are important determinants of investment behaviour and firm valuation. Alm (1988) distinguishes between tax base and tax rate uncertainty to derive welfare effects of tax uncertainty. He argues that uncertain tax policy may be rational for a revenue-maximizing government. Auerbach / Hines (1988) present a model of effective tax rates with time-dependent statutory tax rates, investment tax credits and present value of depreciation allowances to analyze the impact of anticipated tax reforms. However, they use a constant discount factor despite changing tax rates which affect the after-tax discount factor. Skinner (1988) computes the additional excess burden of uncertain compared with certain tax policy. Bizer / Judd (1989) use a dynamic general equilibrium approach, but do not report general results concerning the efficiency costs of random tax policy. Without particular assumptions concerning the distribution of tax parameters, Watson (1992) analyzes saving and investment decisions in a dynamic portfolio model. Under specific conditions, he finds that tax rate uncertainty tends to lower risk-taking.

Since the late 1990s, the tax uncertainty literature focuses on the investment incentives of uncertain tax policy. Alvarez / Kanniainen / Södersten (1998) examine the investment effects of expected tax reforms with uncertain timing. They conclude that an expected reduction of the tax rate induces accelerated investment whereas an expected reduction of the tax base has the opposite effect. These findings are based on the assumption that the opportunity cost of investment is unaffected by taxation because the discount rate is kept constant. Pointon (1998) focuses on imputation tax rates following a Poisson process. Hassett / Metcalf (1999) use a model with an output price following a geometric Brownian motion and an uncertain investment tax credit to explain the effects of tax policy uncertainty on aggregate investment. They conclude that tax policy uncertainty tends to delay investment under a continuous-time random walk, but increases the capital stock under a Poisson jump process.

Since 2000, real option theory has been regularly used to investigate the implications of tax uncertainty. Böhm / Funke (2000) find that the effects of tax policy uncertainty are likely to be small. Agliardi (2001) analyzes investment effects of uncertain investment tax credits following a jump-diffusion process. She finds that tax policy uncertainty delays investment. Panteghini (2001a) derives neutral tax systems under asymmetric taxation with tax rate uncertainty. Panteghini (2001b) uses a Poisson process for the tax rate. He proves that the 
critical investment threshold is unaffected by tax policy uncertainty which means that a neutral stochastic tax system exists.

None of the papers mentioned above takes into account that changes in the nominal tax rate also imply variations in the after-tax discount rate. Moreover, most papers focus on single tax parameters like investment tax credits and do not analyze the combined effects of tax rate and tax base uncertainty.

Niemann (2004) defines tax neutrality in the light of tax uncertainty more precisely. According to his definition, first-order neutrality requires the complete ineffectiveness of taxation on investment decisions. Second-order neutrality means that the stochastic nature of taxation does not alter investment decisions. His analysis of stochastic nominal tax rates includes real as well as financial investment. Since stochastic nominal tax rates affect all assets, a risk-free asset does not exist under tax rate uncertainty. As a consequence, the investment incentives of tax rate uncertainty are ambiguous.

In a model of asset pricing under uncertainty, Sialm (2006) shows that tax uncertainty may be partly responsible for equity premia because price adjustments due to tax changes are larger for long-term assets than for short-term assets.

Hitherto, combined investment incentives and neutrality conditions under multiple tax parameter uncertainty have not been discussed in the literature. Especially, the effects of model-specific tax uncertainty on the optimal design of model tax bases remain to be analyzed $^{2}$. This paper addresses these problems.

\section{Model design}

\subsection{General assumptions}

Following the Dixit / Pindyck (1994) real options model, I consider an option to invest ${ }^{3}$. This option can be regarded as managerial flexibility in the context of non-financial investment. An option to invest provides the opportunity - but not the obligation - to invest in a project with uncertain cash flows ${ }^{4}$ and deterministic or stochastic initial cost. The owner of the option is a potential investor who faces the decision between exercising the option or continuing waiting. Exercise means carrying out the investment project and receiving the resulting cash flows. Waiting implies sacrificing cash flows but avoiding unexpectedly low cash flows. A real options approach always implies a "now-or-later" rather than a "now-or-never" decision

\footnotetext{
${ }^{2}$ Knirsch (2006) analyzes whether detailed tax planning can be more useful than detailed planning of non-tax parameters.

${ }^{3}$ Other possible types of real options are the time-to-build option, the option to abandon, and the generalized option to switch. See Dixit/Pindyck (1994), Trigeorgis (1996).

${ }^{4}$ A similar model design for analyzing tax effects is used by Niemann (1999), Sureth (2002) and Niemann/Sureth (2004).
} 
as assumed in traditional models of capital budgeting. Therefore, an investment project that could be realized immediately has to be compared with the same project when realized later.

For reasons of analytical solubility ${ }^{5}$, I assume a perpetual option to invest and an investment project with infinite economic life ${ }^{6}$. Given the value of the underlying asset, which is given by the investment project's present value, the value of the option to invest can be determined. An option to invest always contains economic value because postponing an investment decision enables to avoid negative net present values resulting from unexpected unfavourable market developments.

I will assume that the investment is completely irreversible. This means that the investor is infinitely bound to the project as soon as he decides to invest. There is no flexibility to sell the investment project at a later point of time.

Modelling the investment project's initial outlay as a stochastic variable does not provide additional insights for tax purposes. Thus, the initial outlay is assumed deterministic and constant and is denoted $I_{0}$. The cash flow generated by the investment project $\pi$ follows an arithmetic Brownian motion ${ }^{7}$ :

$$
d \pi=\alpha_{\pi} d t+\sigma_{\pi} d z_{\pi},
$$

where $\alpha_{\pi}$ and $\sigma_{\pi}$ are drift and volatility parameters, respectively. $d z_{\pi}$ is the increment of a standard Wiener process.

As long as the option to invest is not exercised, available funds yield the risk-free constant capital market rate $r$ which is used as the pre-tax discount rate.

In this paper, I will focus on a risk-neutral investor, because important effects of tax uncertainty under irreversibility can already be observed in this simplified setting ${ }^{8}$.

\subsection{Tax assumptions}

The tax payment attributable to an investment project is the product of the tax base and the tax rate, both of which are subject to frequent fluctuations ${ }^{9}$. As a consequence, the tax payment itself rather than the tax base or the tax rate can be modelled as a stochastic process.

\footnotetext{
${ }^{5}$ Analytical solutions of the investment problem are necessary for the comparative statics in section 5 .

${ }^{6}$ Otherwise, the resulting investment problem would involve partial differential equations that could not be solved analytically.

${ }^{7}$ In financial option pricing, the prevailing stochastic process is a geometric Brownian motion. However, a geometric Brownian motion can only reach non-negative values. In real option theory, it is useful to take negative cash flows (losses) into account which is possible by assuming an arithmetic Brownian motion.

${ }^{8}$ Of course, it would be desirable to take risk-averse investors into consideration, but this assumption would complicate the analysis dramatically and make analytical solutions of the investment problem almost impossible.

${ }^{9}$ Alm (1988) uses a model in which either the tax rate or the tax base are uncertain. Scholes et al. (2005), pp. $69 \mathrm{f}$. discuss the effects of deterministically changing tax rates.
} 
I assume that the tax payment $\tau$ follows an arithmetic Brownian motion with drift $\alpha_{\tau}$ and volatility $\sigma_{\tau}$ :

$$
d \tau=\alpha_{\tau} d t+\sigma_{\tau} d z_{\tau}
$$

where $d z_{\tau}$ is the increment of a standard Wiener process that can be correlated with the cash flow process $d z_{\pi}$ :

$$
E\left[d z_{\pi} d z_{\tau}\right]=\rho d t
$$

The parameter $\rho$ represents the correlation coefficient of the stochastic processes $\pi$ and $\tau$. In models of deterministic taxation, there is typically a linear relation between cash flows and tax payment. My model also takes model-specific tax uncertainty into account and allows for a non-perfect (or even negative) correlation of cash flows and tax payment.

The after-tax cash flow $\pi_{\tau}$ which is relevant for the valuation of the investment project is simply defined as the difference of pre-tax cash flows $\pi$ and the tax payment $\tau$ :

$$
\pi_{\tau}=\pi-\tau .
$$

Since $\pi_{\tau}$ is defined as the difference of two arithmetic Brownian motions, it also follows an arithmetic Brownian motion with drift $\alpha$ and volatility $\sigma$ :

$$
\begin{aligned}
& d \pi_{\tau}=\alpha d t+\sigma d z, \\
& \alpha=\alpha_{\pi}-\alpha_{\tau}, \\
& \sigma=\sqrt{\sigma_{\pi}^{2}+\sigma_{\tau}^{2}-2 \rho \sigma_{\pi} \sigma_{\tau}} .
\end{aligned}
$$

As long as the investment is not realized, available funds are invested at the risk-free capital market rate $r$. I assume that interest income is taxed at the constant rate $s$. Interest taxation is assumed deterministic because there is neither model-specific tax uncertainty nor fiscal tax base uncertainty for financial investment. Furthermore, neglecting tax rate uncertainty for financial investment can be justified by the fact that many jurisdictions levy special tax rates on capital income that undergo less frequent changes. Accepting this assumption, the after-tax discount rate $r_{\tau}$ is given by:

$$
r_{\tau}=(1-s) r
$$




\section{Solving the investment problem}

The solution of the investment problem is given by the critical threshold $\pi_{\tau}^{*}$ of the after-tax cash flow at which the option to invest will be exercised. Solving the problem requires to determine the value of the investment project as well as the value of the option to invest.

When the option is exercised, investment is carried out, and the investment project offers no flexibility at all. As a consequence, the only benefit from the project for the risk-neutral investor is the expected present value from its cash flows. The project value $V\left(\pi_{\tau}\right)$ is given by:

$$
\begin{aligned}
V\left(\pi_{\tau}\right) & =E\left[\int_{0}^{\infty} \pi_{\tau}(t) e^{-r_{\tau} t} d t\right] \\
& =\int_{0}^{\infty}\left(\pi_{0}-\tau_{0}+t \alpha\right) e^{-r_{\tau} t} d t \\
& =\frac{\pi_{0}-\tau_{0}}{r_{\tau}}+\frac{\alpha_{\pi}-\alpha_{\tau}}{r_{\tau}^{2}} .
\end{aligned}
$$

Obviously, the project value increases with an increasing drift of the after-tax cash flows and decreases with an increasing after-tax discount rate.

Determining the option value is necessary to derive the optimal investment rule. Since the owner of the option can only decide between waiting or exercising, valuation requires the separation of the continuation region and the stopping region. Figure 1 illustrates the situation graphically:

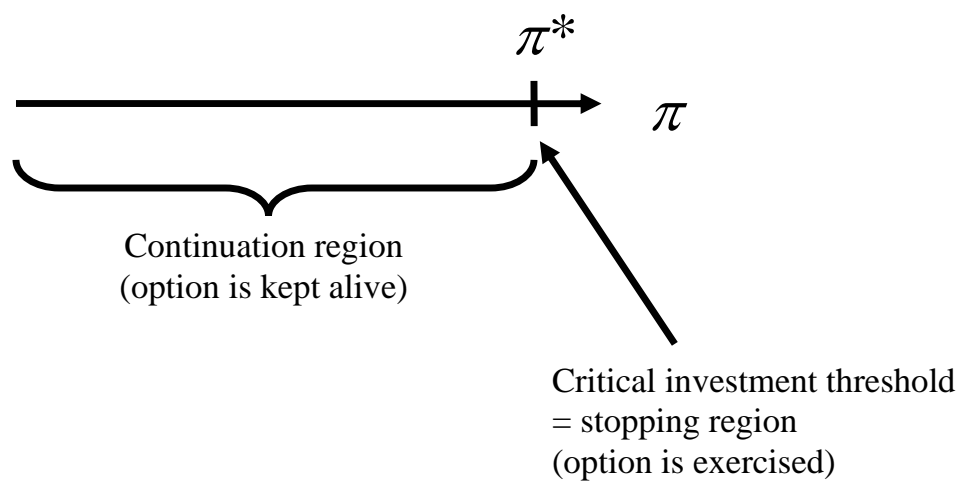

Figure 1: Continuation region and stopping region.

The analytical derivation of the option value is based on dynamic programming ${ }^{10}$. If the stochastic process $\pi_{\tau}$ is inside the continuation region at time $t$, reaching the stopping region

\footnotetext{
${ }^{10}$ In the model presented here, constructing a hedge portfolio is considered inappropriate, because neither short selling of the investment project nor spanning of its cash flow distribution by existing securities is realistic. A comparison of dynamic programming and contingent claims analysis is provided by Niemann/Sureth (2005).
} 
and exercising the option within the next infinitesimal time interval $[t ; t+d t]$ can be excluded almost certainly. Since the option to invest does not provide current cash flows, its only benefit is a possible capital gain. A risk-neutral investor is willing to hold the option only if its expected increase in value $E\left[d F_{\tau}\right]$ equals the risk-free return on the option value $F_{\tau}$ during a time interval of length $d t$ :

$$
r_{\tau} F_{\tau} d t=E\left[d F_{\tau}\right]
$$

After some transformations ${ }^{11}$, the option value in the continuation region is given by:

$$
F_{\tau}\left(\pi_{\tau}\right)=C_{1} e^{\lambda_{1} \pi_{\tau}}
$$

where $\lambda_{1}=-\frac{\alpha}{\sigma^{2}}+\sqrt{\left(\frac{\alpha}{\sigma^{2}}\right)^{2}+\frac{2 r_{\tau}}{\sigma^{2}}}$. To determine the critical investment threshold, two free boundary conditions have to be looked at. It can be proved ${ }^{12}$ that continuity and differentiability at the investment threshold are needed to ensure that the exercise is optimal. The value matching condition (continuity) requires the identity of the project value and the option value plus initial outlay at the optimal point of exercise $\pi_{\tau}^{*}$ :

$$
\begin{gathered}
V\left(\pi_{\tau}^{*}\right)=I_{0}+F_{\tau}\left(\pi_{\tau}^{*}\right) \\
\frac{\pi_{\tau}^{*}}{r_{\tau}}+\frac{\alpha}{r_{\tau}^{2}}=I_{0}+C_{1} e^{\lambda_{1} \pi_{\tau}^{*}} .
\end{gathered}
$$

Interpreting this boundary condition economically, it implies that a project should not be realized unless its benefits equal at least its costs. These costs include the initial outlay as well as the option value that is lost by exercising.

The smooth pasting condition (differentiability) is derived by differentiating the value matching condition with respect to the random variable $\pi_{\tau}$. It can be interpreted as the identity of marginal costs and marginal benefits of the investment in the optimum:

$$
\begin{aligned}
\frac{d V\left(\pi_{\tau}^{*}\right)}{d \pi_{\tau}} & =\frac{F_{\tau}\left(\pi_{\tau}^{*}\right)}{d \pi_{\tau}} \\
\frac{1}{r_{\tau}} & =\lambda_{1} C_{1} e^{\lambda_{1} \pi_{\tau}^{*}} .
\end{aligned}
$$

Since the investment threshold $\pi_{\tau}^{*}$ is to be determined as part of the solution, the investment problem constitutes a free-boundary problem. In case of a perpetual option, the critical

\footnotetext{
${ }^{11}$ A detailed derivation is provided in Appendix A.

${ }^{12}$ See Dixit (1993), p. 31; Dixit/Pindyck (1994), pp. 130 ff.
} 
threshold $\pi_{\tau}^{*}$ is a time-invariant real number that can be derived by dividing eq. (12) by eq. (13):

$$
\pi_{\tau}^{*}=r_{\tau} I_{0}-\frac{\alpha}{r_{\tau}}+\frac{1}{\lambda_{1}}
$$

This critical threshold determines the optimal investment rule: If the current realisation of the stochastic process $\pi_{\tau}$ is less than $\pi_{\tau}^{*}$, the investor should continue waiting and keep the option alive. As soon as the stochastic process reaches $\pi_{\tau}^{*}$, the investor should exercise the option to invest immediately. The pre-tax investment threshold $\pi^{*}$ as a reference case emerges if all tax parameters equal zero: $s=\alpha_{\tau}=\sigma_{\tau}=\tau_{0}=0$ :

$$
\pi^{*}=r I_{0}-\frac{\alpha_{\pi}}{r}+\frac{1}{-\frac{\alpha_{\pi}}{\sigma_{\pi}^{2}}+\sqrt{\left(\frac{\alpha_{\pi}}{\sigma_{\pi}^{2}}\right)^{2}+\frac{2 r}{\sigma_{\pi}^{2}}}} .
$$

Using the optimal investment threshold from eq. (14), the option coefficient $C_{1}$ is given by:

$$
C_{1}=\frac{1}{r_{\tau} \lambda_{1}} e^{\frac{\alpha \lambda_{1}}{r_{\tau}}-\lambda_{1} r_{\tau} I_{0}-1} .
$$

\section{Properties of the optimal investment rule}

The impact of tax uncertainty on investment behaviour can be analyzed by comparative statics, i.e. by computing the partial derivatives of the critical investment threshold $\pi_{\tau}^{*}$ with respect to the tax parameters $\alpha_{\tau}, \sigma_{\tau}$, and $s$.

The investment effects of increasing the drift of the tax payment $\alpha_{\tau}$ can be derived as follows ${ }^{13}$ :

$$
\begin{aligned}
\frac{\partial \pi_{\tau}^{*}}{\partial \alpha_{\tau}} & =\frac{\partial \pi_{\tau}^{*}}{\partial \alpha} \frac{\partial \alpha}{\partial \alpha_{\tau}} \\
& =\frac{1}{r_{\tau}}-\frac{1}{2 r_{\tau}+\alpha\left(\frac{\alpha}{\sigma^{2}}-\sqrt{\frac{\alpha^{2}+2 r_{\tau} \sigma^{2}}{\sigma^{4}}}\right)}>0 .
\end{aligned}
$$

This means that an increase of the drift parameter $\alpha_{\tau}$ has an unambiguous impact on investment behaviour: A higher expected tax payment increases the critical investment

\footnotetext{
${ }^{13}$ A detailed derivation is provided in Appendix B.
} 
threshold and tends to delay investment. In contrast, increasing the drift of the pre-tax cash flow process $\alpha_{\pi}$ has the opposite effect.

This result is especially relevant with regard to model-specific tax uncertainty. An investor whose model tax payment underestimates (overestimates) the actual tax payment would invest prematurely (delayed) compared to the optimal investment policy. In many models of capital budgeting with taxes, the tax base is simply defined as the difference of cash flows and depreciation deductions. This means that tax base elements like provisions, inventories, lossoffset limitations or alternative minimum taxes are neglected. For particular industries with high levels of provisions or inventories, e.g., an incorrect model tax base arises which may induce a systematically wrong investment timing ${ }^{14}$.

Increasing the volatility of the after-tax cash flow also has an unambiguous impact on investment behaviour:

$$
\frac{\partial \pi_{\tau}^{*}}{\partial \sigma}=\frac{1}{\sigma \sqrt{\frac{\alpha^{2}+2 r_{\tau} \sigma^{2}}{\sigma^{4}}}}>0 .
$$

Contrary to traditional models of capital budgeting, volatility affects investment behaviour even when investors are risk-neutral. This result corresponds to traditional option pricing theory because higher volatility ceteris paribus induces higher option values. In contrast, due to the risk neutrality assumption, the project value is unaffected by volatility. For profitable investment, the investor needs a higher project value to be compensated for the increased option value, which leads to a higher critical investment threshold.

However, tax volatility is only one component of total volatility. To isolate the effects of increased tax volatility, the partial derivative with respect to $\sigma_{\tau}$ can be computed:

$$
\begin{aligned}
\frac{\partial \pi_{\tau}^{*}}{\partial \sigma_{\tau}} & =\frac{\partial \pi_{\tau}^{*}}{\partial \sigma} \frac{\partial \sigma}{\partial \sigma_{\tau}} \\
& =\frac{1}{\sigma \sqrt{\frac{\alpha^{2}+2 r_{\tau} \sigma^{2}}{\sigma^{4}}}} \frac{\sigma_{\tau}-\rho \sigma_{\pi}}{\sigma} \\
& =\frac{\sigma_{\tau}-\rho \sigma_{\pi}}{\sqrt{\alpha^{2}+2 r_{\tau} \sigma^{2}}} .
\end{aligned}
$$

Whereas the denominator in eq. (19) is strictly positive, the sign of the numerator depends on the correlation of the tax process and the cash flow process. Thus, the impact of higher tax volatility is ambiguous. Assuming a highly positive correlation, high cash flow volatility and

\footnotetext{
${ }^{14}$ Knirsch (2006) analyzes the impact of various model tax bases on the anticipated future value of different industries in Germany.
} 
low tax volatility, an increase in tax volatility may even lower the critical investment threshold and accelerate investment:

$$
\left.\frac{\partial \pi_{\tau}^{*}}{\partial \sigma_{\tau}}\right|_{\rho \rightarrow 1, \sigma_{\tau}<<\sigma_{\pi}}<0
$$

This apparently counterintuitive result means that increased tax rate uncertainty may accelerate investment under specific conditions ${ }^{15}$. Again, the popular opinion that tax uncertainty always depresses investment can be disproved.

If tax volatility always equals the product of cash flow volatility and the correlation coefficient, an infinitesimal change of tax volatility has no impact on investment timing, as the following condition shows:

$$
\begin{aligned}
& \frac{\partial \pi_{\tau}^{*}}{\partial \sigma_{\tau}}=0 \\
\Leftrightarrow & \sigma_{\tau}=\rho \sigma_{\pi} .
\end{aligned}
$$

Varying the volatility of the pre-tax cash flow $\sigma_{\pi}$ induces ambiguous effects on investment timing:

$$
\frac{\partial \pi_{\tau}^{*}}{\partial \sigma_{\pi}}=\frac{\partial \pi_{\tau}^{*}}{\partial \sigma} \frac{\partial \sigma}{\partial \sigma_{\pi}}=\frac{\sigma_{\pi}-\rho \sigma_{\tau}}{\sqrt{\alpha^{2}+2 r_{\tau} \sigma^{2}}}\left\{\begin{array}{l}
> \\
= \\
<
\end{array}\right\} 0 .
$$

If cash flow volatility exceeds tax volatility, increased cash flow volatility tends to delay investment.

Whereas increasing the pre-tax interest rate reduces investment in traditional models of capital budgeting, real option theory shows that variations of the pre-tax interest rate $r$ may have an ambiguous impact on the critical investment threshold. Depending on the particular parameter setting, the critical threshold $\pi_{\tau}^{*}$ can increase, decrease, or remain constant if the pre-tax interest rate is raised:

$$
\begin{aligned}
\frac{\partial \pi_{\tau}^{*}}{\partial r}= & (1-s) I_{0}+\frac{\alpha}{r^{2}(1-s)} \\
& -\frac{(1-s) \sigma^{2}}{\frac{1}{\sigma^{2}} \sqrt{\alpha^{2}+2 r(1-s) \sigma^{2}}\left(\alpha-\sqrt{\alpha^{2}+2 r(1-s) \sigma^{2}}\right)^{2}}\left\{\begin{array}{l}
> \\
= \\
<
\end{array}\right\} .
\end{aligned}
$$

This result is illustrated in figure 2 which is based on the parameters $I_{0}=1 ; r=0.08$; $\alpha=0.04 ; \sigma=0.18$ :

\footnotetext{
${ }^{15}$ This result corresponds to the findings by Niemann (2004).
} 


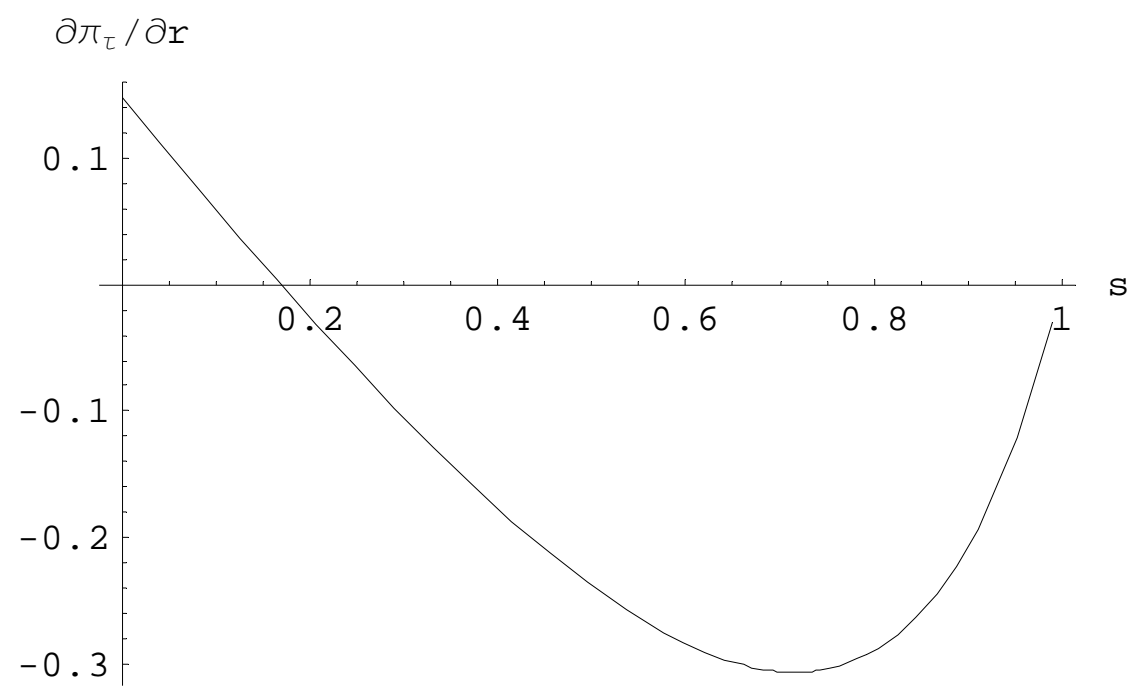

Figure 2: Partial derivative of the critical investment threshold w.r.t. the pre-tax interest rate as a function of $s$.

In accordance with traditional capital budgeting, the project value decreases when the interest rate increases. However, the option value may increase, decrease, or remain constant when the interest rate is increased. If the reduction of the option value exceeds the reduction of the project value, an apparently paradox effect emerges and investment is accelerated by a higher pre-tax interest rate.

Varying the tax rate $s$ on financial investment also induces ambiguous results and depends on the parameter setting under consideration:

$$
\begin{aligned}
\frac{\partial \pi_{\tau}^{*}}{\partial s}= & -r I_{0}-\frac{\alpha}{r(1-s)^{2}} \\
& +\frac{r}{\sigma^{2}\left(\sqrt{\frac{\alpha^{2}}{\sigma^{4}}+\frac{2 r(1-s)}{\sigma^{2}}}-\frac{\alpha}{\sigma^{2}}\right)^{2} \sqrt{\frac{\alpha^{2}}{\sigma^{4}}+\frac{2 r(1-s)}{\sigma^{2}}}}\left\{\begin{array}{l}
> \\
=\} \\
<
\end{array} 0 .\right.
\end{aligned}
$$

The following example illustrates this result. For the parameter setting from figure 2 ( $\left.I_{0}=1 ; r=0.08 ; \alpha=0.04 ; \sigma=0.18\right)$, the partial derivative $\frac{\partial \pi_{\tau}^{*}}{\partial s}$ may take either sign, depending on the current level of $s$, as is shown in figure 3: 


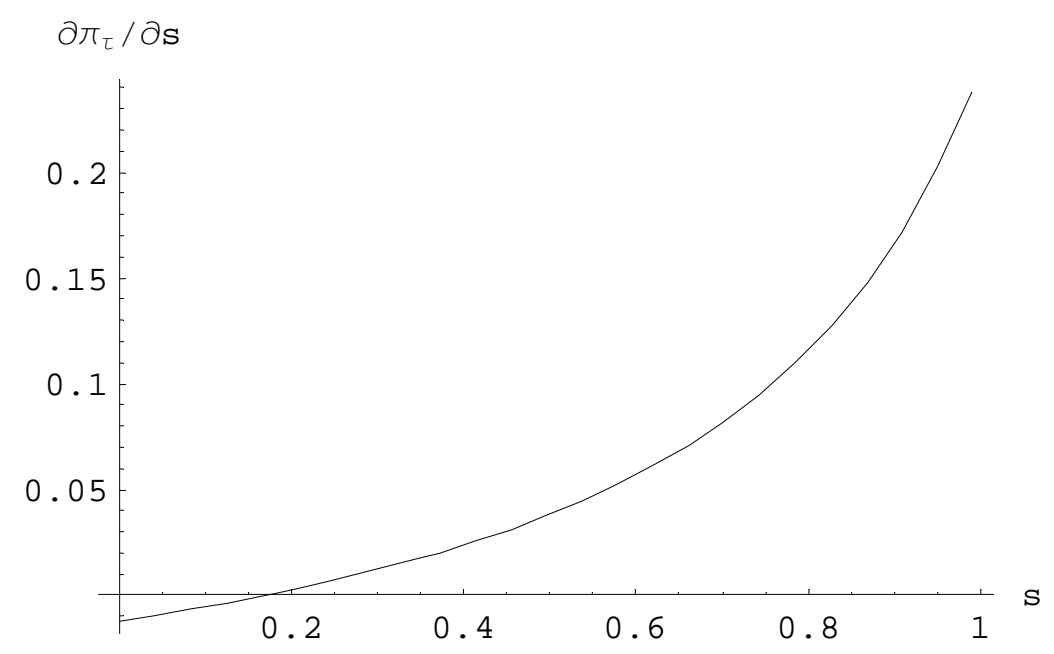

Figure 3: Partial derivative of the critical investment threshold w.r.t. the tax rate on interest income as a function of $s$.

Obviously, the critical investment threshold can increase, decrease, or remain constant if the tax rate on interest income is raised. At first glance, this result seems implausible because the tax rate $s$ applies only for interest income and is irrelevant for real investment. However, the tax rate $s$ affects the after-tax interest rate $r_{\tau}$ which determines the option value. As shown above, the impact of interest rate variations on the option value and hence the investment threshold is ambiguous.

\section{Neutral tax systems}

Tax systems which do no affect investment behaviour are called neutral. Typically, neutral tax systems are derived assuming that cash flows and tax payments are deterministic. The neutrality property has to be defined more precisely ${ }^{16}$ if tax uncertainty is taken into account. In a real options model, first-order neutrality requires the identity of the critical investment thresholds before and after taxes. Basically, it would be possible to derive neutral tax systems by equating the critical thresholds ${ }^{17} \pi^{*}$ and $\pi_{\tau}^{*}$ from eqs. (15) and (14) and solving for the parameters of the stochastic processes. However, it is not feasible to compare these thresholds directly, because the after-tax threshold $\pi_{\tau}^{*}$ is a combination of two processes whereas $\pi^{*}$ is only based on a single process. From the neutrality condition, it follows immediately that only taxation with an expected value zero ( $s=E[\tau]=0 \forall t$ ) could ensure first-order neutrality. As a consequence, this model does not allow the derivation of non-zero first-order neutral stochastic tax systems by identifying adequate tax process parameters.

\footnotetext{
${ }^{16}$ See Niemann (2004), p. 271.

${ }^{17}$ For deterministic tax systems, this procedure is chosen by Niemann/Sureth (2005).
} 
However, a special case of first-order neutral stochastic taxation can be described as a stochastic poll tax: If a taxpayer cannot escape taxation whatever his economic decisions, whether investment is realized or not, then even stochastic taxation does not affect the investment behaviour of risk-neutral investors. Of course, such a tax system would be regarded politically unacceptable.

A tax system is second-order neutral if the critical investment thresholds for stochastic and deterministic taxation correspond. Hence, the neutrality condition is:

$$
\begin{aligned}
\left.\pi_{\tau}^{*}\right|_{\sigma_{\tau}>0} & =\left.\pi_{\tau}^{*}\right|_{\sigma_{\tau}=0} \\
r_{\tau} I_{0}-\frac{\alpha}{r_{\tau}}+\frac{1}{\lambda_{1}} & =r_{\tau} I_{0}-\frac{\alpha}{r_{\tau}}+\frac{1}{\left.\lambda_{1}\right|_{\sigma_{\tau}=0}} \\
\left.\lambda_{1}\right|_{\sigma_{\tau}>0} & =\left.\lambda_{1}\right|_{\sigma_{\tau}=0} \\
-\frac{\alpha}{\sigma^{2}}+\sqrt{\left(\frac{\alpha}{\sigma^{2}}\right)^{2}+\frac{2 r_{\tau}}{\sigma^{2}}} & =-\frac{\alpha}{\sigma_{\pi}^{2}}+\sqrt{\left(\frac{\alpha}{\sigma_{\pi}^{2}}\right)^{2}+\frac{2 r_{\tau}}{\sigma_{\pi}^{2}}} \\
\sigma & =\sigma_{\pi} \\
\sigma_{\tau} & =2 \rho \sigma_{\pi} .
\end{aligned}
$$

In this model setting, stochastic second-order neutral tax systems are characterized by a positive correlation of tax payment and cash flows. The volatility of the tax payment is a function of the cash flow volatility that ensures exactly corresponding volatilities of the pretax and the after-tax cash flows. This means that any second-order neutral tax system must be adapted to the specific cash flow process under consideration. In reality, of course, this requirement is incompatible with legal certainty. Moreover, a tax system that anticipates its own uncertainty seems rather unrealistic.

\section{Summary and conclusion}

I have analyzed the impact of tax uncertainty on optimal investment behaviour in a real options model, taking the effects of uncertainty and irreversibility into account. I modelled combined tax rate and tax base uncertainty by assuming a stochastic tax payment following an arithmetic Brownian motion. If the stochastic cash flow also follows an arithmetic Brownian motion the investment problem can be solved analytically. The solution is given by the critical threshold of the after-tax cash flow at which immediate investment is optimal. By differentiating the critical threshold with respect to the parameters of the stochastic processes, it is easy to perform comparative-static analyses.

The most striking result is the finding that increased tax uncertainty does not necessarily delay investment. This outcome is consistent with the existing literature ${ }^{18}$. Investment can be

\footnotetext{
${ }^{18}$ See Niemann (2004).
} 
accelerated by increased tax uncertainty if tax uncertainty is small compared to cash flow uncertainty and if both processes are positively correlated. As expected, an increase in the tax payment delays investment. Both effects of varying the tax rate on interest income and the pre-tax interest rate are ambiguous.

Although the investment model does not permit stochastic first-order neutral tax systems, it is easy to derive second-order neutral tax systems. These tax systems imply that the volatility of the after-tax cash flow equals the volatility of the pre-tax cash flow.

Whereas it is rather difficult to draw immediate conclusions for tax policy, my model provides important insights for investors facing tax uncertainty. If investors systematically under- or overestimate the tax payment attributable to an investment project, wrong investment decisions will occur. This effect is likely if investors neglect particular tax base elements in their models. However, real tax systems are often too complex to be modelled in detail. As a consequence, it may be useful for investors to apply investment models with stochastic taxation rather than oversimplified or misspecified models of deterministic taxation.

Modelling tax uncertainty explicitly may solve two problems simultaneously: By carefully estimating the parameters of the tax process in the model investors are enabled to handle fiscal tax uncertainty as well as model-specific tax uncertainty. Further, complexity with regard to the investment model's tax base can be limited which reduces tax planning costs. 


\section{Appendix A}

Using dynamic programming, the Hamilton-Jacobi-Bellman equation for valuing the option to invest is given by eq. (10):

$$
r_{\tau} F_{\tau} d t=E\left[d F_{\tau}\right]
$$

Since the option value $F_{\tau}$ is a function of the stochastic process $\pi_{\tau}$, ordinary calculus is not applicable. Rather, Itô's lemma ${ }^{19}$ is needed for transforming functions of stochastic variables. The stochastic differential of the time-invariant ${ }^{20}$ function $F_{\tau}\left(\pi_{\tau}\right)$ is given by:

$$
\begin{aligned}
d F_{\tau} & =\frac{\partial F_{\tau}}{\partial t} d t+\frac{\partial F_{\tau}}{\partial \pi_{\tau}} d \pi_{\tau}+\frac{1}{2} \frac{\partial^{2} F_{\tau}}{\partial \pi_{\tau}^{2}}\left(d \pi_{\tau}\right)^{2} \\
& =\frac{\partial F_{\tau}}{\partial t} d t+\alpha \frac{\partial F_{\tau}}{\partial \pi_{\tau}} d t+\frac{1}{2} \sigma^{2} \frac{\partial^{2} F_{\tau}}{\partial \pi_{\tau}^{2}} d t+\sigma \frac{\partial F_{\tau}}{\partial \pi_{\tau}} d z+o(d t),
\end{aligned}
$$

where $o(d t)$ summarizes all terms converging faster than $d t: \lim _{d t \rightarrow 0} \frac{o(d t)}{d t}=0$. Using $E[d z]=0$ and dividing by $d t$, eq. (A 1 ) can be transformed to the ordinary differential equation:

$$
\frac{1}{2} \sigma^{2} \frac{d^{2} F_{\tau}}{d \pi_{\tau}^{2}}+\alpha \frac{d F_{\tau}}{d \pi_{\tau}} d t-r_{\tau} F_{\tau}=0
$$

with the general solution

$$
F_{\tau}\left(\pi_{\tau}\right)=C_{1} e^{\lambda_{1} \pi_{\tau}}+C_{2} e^{\lambda_{2} \pi_{\tau}} .
$$

$C_{1}$ and $C_{2}$ are constants to be defined, and $\lambda_{1}, \lambda_{2}$ are the positive and negative root of the characteristic equation of eq. (A 3): $\lambda_{1 / 2}=-\frac{\alpha}{\sigma^{2}} \pm \sqrt{\left(\frac{\alpha}{\sigma^{2}}\right)^{2}+\frac{2 r_{\tau}}{\sigma^{2}}}$, with $\lambda_{1}>0, \lambda_{2}<0$.

For $\pi_{\tau} \rightarrow-\infty$, the value of the project becomes infinitely negative, so the option to invest must be worthless in this case:

$$
\lim _{\pi_{\tau} \rightarrow-\infty} F\left(\pi_{\tau}\right)=0
$$

Hence, the coefficient $C_{1}$ is positive, $C_{2}$ must be zero, and the option value in the continuation region is given by:

$$
F_{\tau}\left(\pi_{\tau}\right)=C_{1} e^{\lambda_{1} \pi_{\tau}}
$$

\footnotetext{
${ }^{19}$ See Itô (1951), Øksendal (1998), e.g.

${ }^{20}$ Note that the option to invest is a perpetual option. As a consequence, the time derivative does not arise in eq. (A 3).
} 


\section{Appendix B}

The investment effects of increasing the drift of the tax payment $\alpha_{\tau}$ can be derived as follows:

$$
\frac{\partial \pi_{\tau}^{*}}{\partial \alpha_{\tau}}=\frac{\partial \pi_{\tau}^{*}}{\partial \alpha} \frac{\partial \alpha}{\partial \alpha_{\tau}}=\frac{1}{r_{\tau}}-\frac{1}{2 r_{\tau}+\alpha\left(\frac{\alpha}{\sigma^{2}}-\sqrt{\frac{\alpha^{2}+2 r_{\tau} \sigma^{2}}{\sigma^{4}}}\right)}
$$

Since the sign of this partial derivative is not obvious, three different cases have to be considered:

1. $\left.\frac{\partial \pi_{\tau}^{*}}{\partial \alpha_{\tau}}\right|_{\alpha=0}=\frac{1}{r_{\tau}}-\frac{1}{2 r_{\tau}}=\frac{1}{2 r_{\tau}}>0$,
2. $\left.\frac{\partial \pi_{\tau}^{*}}{\partial \alpha_{\tau}}\right|_{\alpha<0}=\frac{1}{r_{\tau}}-\frac{1}{2 r_{\tau}+\underbrace{\alpha\left(\frac{\alpha}{\sigma^{2}}-\sqrt{\left.\frac{\alpha^{2}+2 r_{\tau} \sigma^{2}}{\sigma^{4}}\right)}\right.}_{>0}>0,}$

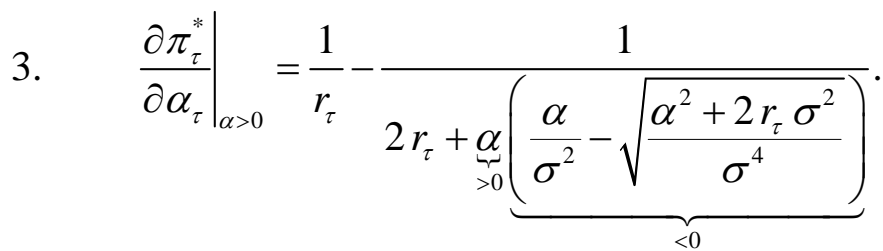

The expression in eq. (B 4) is positive, if the following condition holds:

$$
\begin{aligned}
& \alpha\left(\frac{\alpha}{\sigma^{2}}-\sqrt{\frac{\alpha^{2}+2 r_{\tau} \sigma^{2}}{\sigma^{4}}}\right)>-r_{\tau} \\
\Leftrightarrow & \alpha-\sqrt{\alpha^{2}+2 r_{\tau} \sigma^{2}}>-\frac{r_{\tau} \sigma^{2}}{\alpha} \\
\Leftrightarrow & -\sqrt{\alpha^{2}+2 r_{\tau} \sigma^{2}}>-\frac{r_{\tau} \sigma^{2}}{\alpha}-\alpha \\
\Leftrightarrow & \sqrt{\alpha^{2}+2 r_{\tau} \sigma^{2}}<\frac{r_{\tau} \sigma^{2}}{\alpha}+\alpha \\
\Rightarrow & \alpha^{2}+2 r_{\tau} \sigma^{2}<\left(\frac{r_{\tau} \sigma^{2}}{\alpha}+\alpha\right)^{2}=\frac{r_{\tau}^{2} \sigma^{4}}{\alpha^{2}}+\alpha^{2}+2 r_{\tau} \sigma^{2} \\
\Leftrightarrow & 0<\frac{r_{\tau}^{2} \sigma^{4}}{\alpha^{2}} .
\end{aligned}
$$

Since the last statement in eq. (B 5) is true, $\left.\frac{\partial \pi_{\tau}^{*}}{\partial \alpha_{\tau}}\right|_{\alpha>0}>0$ also holds. Hence, $\frac{\partial \pi_{\tau}^{*}}{\partial \alpha_{\tau}}>0 \forall \alpha$. 


\section{References}

Agliardi, Elettra (2001): Taxation and Investment Decisions - A Real Option Approach, in: Australian Economic Papers 40, 44-55.

Alm, James (1988): Uncertain Tax Policies, Individual Behavior, and Welfare, in: American Economic Review 78, 237-245.

Alvarez, Luis H.R. / Kanniainen, Vesa / Södersten, Jan (1998): Tax Policy Uncertainty and Corporate Investment. A Theory of Tax-Induced Investment Spurts, in: Journal of Public Economics 69, 17-48.

Auerbach, Alan J. / Hines, James R., Jr. (1987): Anticipated Tax Changes and the Timing of Investment, in: Feldstein, Martin (ed.): The Effects of Taxation on Capital Accumulation, University of Chicago Press, Chicago, 163-200.

Auerbach, Alan J. / Hines, James R., Jr. (1988): Investment Tax Incentives and Frequent Tax Reforms, in: American Economic Review, Papers \& Proceedings 78, 211-216.

Bizer, David S. / Judd, Kenneth L. (1989): Taxation and Uncertainty, in: American Economic Review, Papers \& Proceedings 79, 331-336.

Böhm, Hjalmar / Funke, Michael (2000): Optimal Investment Strategies under Demand and Tax Policy Uncertainty, CESifo Working Paper No. 311.

Dixit, Avinash K. (1993): The Art of Smooth Pasting, in: Fundamentals of Pure and Applied Economics 55, 1-72.

Dixit, Avinash K. / Pindyck, Robert S. (1994): Investment under Uncertainty, Princeton University Press, Princeton.

Hassett, Kevin A. / Metcalf, Gilbert E. (1999): Investment with Uncertain Tax Policy: Does Random Tax Policy Discourage Investment?, in: The Economic Journal 109, 372-393.

Itô, Kiyosi (1951): On Stochastic Differential Equations, in: Memoirs of the American Mathematical Society 4, 1-51.

Knirsch, Deborah (2006): Is a Detailed Tax Planning for Investment Decisions Worthwhile?Evidence from Germany, Presentation at the International Conference on Policy Modeling, Hong Kong, China, June 28, 2006, www.ecomod.org/files/papers/1259.pdf.

Niemann, Rainer (1999): Neutral Taxation under Uncertainty - a Real Options Approach, in: FinanzArchiv 56, 51-66.

Niemann, Rainer (2004): Tax Rate Uncertainty, Investment Decisions, and Tax Neutrality, in: International Tax and Public Finance 11, 265-281.

Niemann, Rainer / Sureth, Caren (2004): Tax Neutrality under Irreversibility and Risk Aversion, in: Economics Letters 84, 43-47. 
Niemann, Rainer / Sureth, Caren (2005): Capital Budgeting with Taxes under Uncertainty and Irreversibility, in: Jahrbücher für Nationalökonomie und Statistik 225, 77-95.

Øksendal, Bernt (1998): Stochastic Differential Equations, $5^{\text {th }}$ ed., Springer, Berlin.

Panteghini, Paolo (2001a): On Corporate Tax Asymmetries and Neutrality, in: German Economic Review 2, 269-286.

Panteghini, Paolo (2001b): Corporate Tax Asymmetries under Investment Irreversibility, in: FinanzArchiv 58, 207-226.

Pointon, John (1998): Share Valuation under Geometric Brownian Motion with a Poisson Imputation Tax Change, in: Journal of Business Finance \& Accounting 25, 103-113.

Sialm, Clemens (2006): Stochastic Taxation and Asset Pricing in Dynamic General Equilibrium, in: Journal of Economic Dynamics \& Control 30, 511-540.

Scholes, Myron S. / Wolfson, Mark A. / Erickson, Merle / Maydew, Edward L. / Shevlin, Terry (2005): Taxes and Business Strategy - A Planning Approach, $3^{\text {rd }}$ ed., Prentice Hall, Upper Saddle River.

Skinner, Jonathan (1988): The Welfare Cost of Uncertain Tax Policy, in: Journal of Public Economics 37, 129-145.

Sureth, Caren (2002): Partially Irreversible Investment Decisions and Taxation under Uncertainty: A Real Option Approach, in: German Economic Review 3, 185-221.

Trigeorgis, Lenos (1996): Real Options - Managerial Flexibility and Strategy in Resource Allocation, MIT Press, Cambridge, Massachusetts.

Watson, Harry (1992): The Effects of Income Tax Rate Uncertainty in a Dynamic Setting, in: Southern Economic Journal 58, 683-689.

Weiss, Laurence (1976): The Desirability of Cheating Incentives and Randomness in the Optimal Income Tax, in: Journal of Political Economy 84, 1343-1352. 


\section{CESifo Working Paper Series}

for full list see www.cesifo-group.org/wp

(address: Poschingerstr. 5, 81679 Munich, Germany, office@cesifo.de)

2012 Carlos Alós-Ferrer, Georg Kirchsteiger and Markus Walzl, On the Evolution of Market Institutions: The Platform Design Paradox, June 2007

2013 Axel Dreher and Martin Gassebner, Greasing the Wheels of Entrepreneurship? The Impact of Regulations and Corruption on Firm Entry, June 2007

2014 Dominique Demougin and Claude Fluet, Rules of Proof, Courts, and Incentives, June 2007

2015 Stefan Lachenmaier and Horst Rottmann, Effects of Innovation on Employment: A Dynamic Panel Analysis, June 2007

2016 Torsten Persson and Guido Tabellini, The Growth Effect of Democracy: Is it Heterogenous and how can it be Estimated?, June 2007

2017 Lorenz Blume, Jens Müller, Stefan Voigt and Carsten Wolf, The Economic Effects of Constitutions: Replicating - and Extending - Persson and Tabellini, June 2007

2018 Hartmut Egger and Gabriel Felbermayr, Endogenous Skill Formation and the Source Country Effects of International Labor Market Integration, June 2007

2019 Bruno Frey, Overprotected Politicians, June 2007

2020 Jan Thomas Martini, Rainer Niemann and Dirk Simons, Transfer Pricing or Formula Apportionment? Tax-Induced Distortions of Multinationals' Investment and Production Decisions, June 2007

2021 Andreas Bühn, Alexander Karmann and Friedrich Schneider, Size and Development of the Shadow Economy and of Do-it-yourself Activities in Germany, June 2007

2022 Michael Rauscher and Edward B. Barbier, Biodiversity and Geography, June 2007

2023 Gunther Schnabl, Exchange Rate Volatility and Growth in Emerging Europe and East Asia, June 2007

2024 Erkki Koskela and Ronnie Schöb, Tax Progression under Collective Wage Bargaining and Individual Effort Determination, June 2007

2025 Jay Pil Choi and Marcel Thum, The Economics of Politically Connected Firms, June 2007

2026 Jukka Pirttilä and Roope Uusitalo, Leaky Bucket in the Real World: Estimating Inequality Aversion Using Survey Data, June 2007 
2027 Ruslan Lukach, Peter M. Kort and Joseph Plasmans, Strategic R\&D with Knowledge Spillovers and Endogenous Time to Complete, June 2007

2028 Jarko Fidrmuc, Neil Foster and Johann Scharler, Labour Market Rigidities, Financial Integration and International Risk Sharing in the OECD, June 2007

2029 Bernardina Algieri and Thierry Bracke, Patterns of Current Account Adjustment Insights from Past Experience, June 2007

2030 Robert Dur and Hein Roelfsema, Social Exchange and Common Agency in Organizations, June 2007

2031 Alexander Libman and Lars P. Feld, Strategic Tax Collection and Fiscal Decentralisation: The Case of Russia, June 2007

2032 Øystein Foros, Hans Jarle Kind and Greg Shaffer, Resale Price Maintenance and Restrictions on Dominant Firm and Industry-Wide Adoption, June 2007

2033 Jan K. Brueckner and Kurt Van Dender, Atomistic Congestion Tolls at Concentrated Airports? Seeking a Unified View in the Internalization Debate, June 2007

2034 Viet Do and Ngo Van Long, International Outsourcing under Monopolistic Competition: Winners and Losers, June 2007

2035 Nadia Fiorino and Roberto Ricciuti, Determinants of Direct Democracy, June 2007

2036 Burkhard Heer and Alfred Maussner, Inflation and Output Dynamics in a Model with Labor Market Search and Capital Accumulation, June 2007

2037 Konstantinos Angelopoulos, Jim Malley and Apostolis Philippopoulos, Public Education Expenditure, Growth and Welfare, June 2007

2038 Maarten Bosker, Steven Brakman, Harry Garretsen and Marc Schramm, Adding Geography to the New Economic Geography, June 2007

2039 Steffen Henzel, Oliver Hülsewig, Eric Mayer and Timo Wollmershäuser, The Price Puzzle Revisited: Can the Cost Channel Explain a Rise in Inflation after a Monetary Policy Shock?, July 2007

2040 Rosario Crinò, Service Offshoring and White-Collar Employment, July 2007

2041 Carsten Hefeker and Michael Neugart, Labor Market Regulation and the Legal System, July 2007

2042 Bart Cockx and Muriel Dejemeppe, Is the Notification of Monitoring a Threat to the Unemployed? A Regression Discontinuity Approach, July 2007

2043 Alfons J. Weichenrieder, Profit Shifting in the EU: Evidence from Germany, July 2007 
2044 Annika Alexius and Bertil Holmlund, Monetary Policy and Swedish Unemployment Fluctuations, July 2007

2045 Axel Dreher, Jan-Egbert Sturm and Jakob de Haan, Does High Inflation Cause Central Bankers to Lose their Job? Evidence Based on a New Data Set, July 2007

2046 Guglielmo Maria Caporale and Luis A. Gil-Alana, Long Run and Cyclical Dynamics in the US Stock Market, July 2007

2047 Alessandro Balestrino, It is a Theft but not a Crime, July 2007

2048 Daniel Becker and Michael Rauscher, Fiscal Competition in Space and Time: An Endogenous-Growth Approach, July 2007

2049 Yannis M. Ioannides, Henry G. Overman, Esteban Rossi-Hansberg and Kurt Schmidheiny, The Effect of Information and Communication Technologies on Urban Structure, July 2007

2050 Hans-Werner Sinn, Please bring me the New York Times - On the European Roots of Richard Abel Musgrave, July 2007

2051 Gunther Schnabl and Christian Danne, A Role Model for China? Exchange Rate Flexibility and Monetary Policy in Japan, July 2007

2052 Joseph Plasmans, Jorge Fornero and Tomasz Michalak, A Microfounded Sectoral Model for Open Economies, July 2007

2053 Vesa Kanniainen and Panu Poutvaara, Imperfect Transmission of Tacit Knowledge and other Barriers to Entrepreneurship, July 2007

2054 Marko Koethenbuerger, Federal Tax-Transfer Policy and Intergovernmental PreCommitment, July 2007

2055 Hendrik Jürges and Kerstin Schneider, What Can Go Wrong Will Go Wrong: Birthday Effects and Early Tracking in the German School System, July 2007

2056 Bahram Pesaran and M. Hashem Pesaran, Modelling Volatilities and Conditional Correlations in Futures Markets with a Multivariate t Distribution, July 2007

2057 Walter H. Fisher and Christian Keuschnigg, Pension Reform and Labor Market Incentives, July 2007

2058 Martin Altemeyer-Bartscher, Dirk T. G. Rübbelke and Eytan Sheshinski, Policies to Internalize Reciprocal International Spillovers, July 2007

2059 Kurt R. Brekke, Astrid L. Grasdal and Tor Helge Holmås, Regulation and Pricing of Pharmaceuticals: Reference Pricing or Price Cap Regulation?, July 2007

2060 Tigran Poghosyan and Jakob de Haan, Interest Rate Linkages in EMU Countries: A Rolling Threshold Vector Error-Correction Approach, July 2007 
2061 Robert Dur and Klaas Staal, Local Public Good Provision, Municipal Consolidation, and National Transfers, July 2007

2062 Helge Berger and Anika Holler, What Determines Fiscal Policy? Evidence from German States, July 2007

2063 Ernesto Reuben and Arno Riedl, Public Goods Provision and Sanctioning in Privileged Groups, July 2007

2064 Jan Hanousek, Dana Hajkova and Randall K. Filer, A Rise by Any Other Name? Sensitivity of Growth Regressions to Data Source, July 2007

2065 Yin-Wong Cheung and Xing Wang Qian, Hoarding of International Reserves: Mrs Machlup's Wardrobe and the Joneses, July 2007

2066 Sheilagh Ogilvie, 'Whatever Is, Is Right'?, Economic Institutions in Pre-Industrial Europe (Tawney Lecture 2006), August 2007

2067 Floriana Cerniglia and Laura Pagani, The European Union and the Member States: Which Level of Government Should Do what? An Empirical Analysis of Europeans' Preferences, August 2007

2068 Alessandro Balestrino and Cinzia Ciardi, Social Norms, Cognitive Dissonance and the Timing of Marriage, August 2007

2069 Massimo Bordignon, Exit and Voice. Yardstick versus Fiscal Competition across Governments, August 2007

2070 Emily Blanchard and Gerald Willmann, Political Stasis or Protectionist Rut? Policy Mechanisms for Trade Reform in a Democracy, August 2007

2071 Maarten Bosker and Harry Garretsen, Trade Costs, Market Access and Economic Geography: Why the Empirical Specification of Trade Costs Matters, August 2007

2072 Marco Runkel and Guttorm Schjelderup, The Choice of Apportionment Factors under Formula Apportionment, August 2007

2073 Jay Pil Choi, Tying in Two-Sided Markets with Multi-Homing, August 2007

2074 Marcella Nicolini, Institutions and Offshoring Decision, August 2007

2075 Rainer Niemann, The Impact of Tax Uncertainty on Irreversible Investment, August 2007 